\title{
MICROBIALITOS FÓSSEIS DA FORMAÇÃO JAÍBA, GRUPO BAMBUÍ, MINAS GERAIS, BRASIL
}

\author{
EVELYN A. M. SANCHEZ \\ Centro de Estudos em Geociências, Instituto de Ciência e Tecnologia, Universidade Federal dos Vales do Jequitinhonha \\ e Mucuri, Rodovia MGT 367 - km 583, n 5000, Alto da Jacuba, 39100-000, Diamantina, Minas Gerais, Brasil. \\ evelyn.sanchez@ict.ufvjm.edu.br \\ THAÍS A. VIEIRA \\ Bacharelado em Ciência e Tecnologia, Instituto de Ciência e Tecnologia, Universidade Federal dos Vales do Jequitinhonha \\ e Mucuri, Rodovia MGT 367 - km 583, n 5000, Alto da Jacuba, 39100-000, Diamantina, Minas Gerais, Brasil. \\ thais20vieira@gmail.com \\ HUMBERTO L. S. REIS \\ Departamento de Geologia, Escola de Minas, Universidade Federal de Ouro Preto. Campus Morro do Cruzeiro s/n, Bairro \\ Bauxita, Ouro Preto, Minas Gerais, Brasil.humberto.reis@ufop.edu.br \\ MATHEUS KUCHENBECKER \\ Centro de Estudos em Geociências, Instituto de Ciência e Tecnologia, Universidade Federal dos Vales do Jequitinhonha \\ e Mucuri, Rodovia MGT 367 - km 583, n 5000, Alto da Jacuba, 39100-000, Diamantina, Minas Gerais, Brasil. \\ matheusk@ict.ufvjm.edu.br
}

\begin{abstract}
Fossil microbialites of the Jaíba Formation, Bambuí Group, Minas Gerais, Brazil. Microbialites are carbonatic deposits, whose genesis is organosedimentary, deposited by benthic microbial mats. Microbialites are the most common fossils in rocks of the Proterozoic, worldwide and in Brazil. They exhibit morphological diversity since the oldest Archean forms, and are fundamental in studies concerning the biota and environmental aspects of past times, allowing better comprehension of biological and carbonate biosedimentary evolution through time. Microbial laminites and thrombolites of the Jaíba Formation, upper Bambuí Group, are described. Thrombolites show columnar and irregular shape, centimetric size, and are locally coalescent. Laminites, overlying the thrombolitic strata, display smooth, wavy, and crenulate synoptic relief. Five microfabrics and microfossils of two distinct morphologies, coccoidal and filamentous, were identified. Microfabrics may be of biogenic or abiogenic origin, representing different processes involved in the formation of microbialites. Thus, microbialites and microfossils of the Jaíba Formation show potential to better understand the producer biota in the context of the Ediacaran-Cambrian transition, probable age of this unit, and an important moment of profound changes in biosphere, due to the diversification of metazoans.
\end{abstract}

Keywords: thrombolites, laminites, microfabrics, Neoproterozoic, Cambrian.

RESUMO - Os microbialitos são depósitos carbonáticos cuja origem é organossedimentar, depositados por esteiras microbianas bentônicas. Microbialitos são os fósseis mais comuns encontrados no Brasil e no mundo em rochas do Proterozoico. Apresentam diversidade morfológica desde as formas mais antigas, datadas do Arqueano, e são fundamentais nos estudos da paleobiota e aspectos ambientais pretéritos, permitindo o melhor entendimento da evolução biológica e biossedimentar carbonática ao longo do tempo geológico. Neste trabalho são descritos laminitos e trombólitos da Formação Jaíba, na porção superior do Grupo Bambuí. Os trombólitos encontrados apresentam formas colunares e irregulares, centimétricas e pontualmente coalescentes. Já os laminitos microbiais, sobrejacentes aos trombólitos, apresentam laminações com relevo sinóptico entre plano, ondulado e crenulado. Cinco microtexturas e microfósseis de duas morfologias distintas, cocoides e filamentosos, foram identificados. As microtexturas são de origem biogênica e abiogênica, e representam os diferentes processos de formação dos microbialitos. Dessa forma, os microbialitos e microfósseis encontrados na Formação Jaíba apresentam potencial para melhor compreender a paleobiota produtora no contexto da transição Ediacarano-Cambriano, provável idade desta unidade, um momento importante de mudanças profundas na biosfera, devido à diversificação dos metazoários.

Palavras-chave: trombólitos, laminitos microbiais, texturas, Neoproterozoico, Cambriano. 


\section{INTRODUÇÃO}

Microbialitos são depósitos organossedimentares gerados a partir da precipitação mineral ou deposição detrítica ocasionada pela presença de esteiras microbianas bentônicas (Burne \& Moore, 1987). Estes fósseis estão entre as formas mais comuns do Proterozoico, encontradas em diversos registros no mundo (Walter et al., 1992) e no Brasil (ver discussão em Fairchild \& Sanchez, 2015). Ao longo deste éon, microbialitos se desenvolveram em diferentes ambientes deposicionais marinhos, lacustres e transicionais, desde supramaré até águas profundas, o que reflete a adaptação da vida procariótica aos mais variados biótopos. Esta adaptação pode, inclusive, explicar alguns aspectos da grande variedade morfológica entre os microbialitos, que contaram com mais de 400 morfotipos conhecidos até o momento (Riding, 2006). Durante o Proterozoico, os microbialitos passaram a desempenhar um papel importante na dinâmica de ambientes costeiros: tornaram-se os formadores de recifes, as quais eram, e ainda são, importantes feições fisiográficas e, hoje, compõem extensos corpos carbonáticos (Wood, 2015), inclusive com importância econômica. Portanto, o estudo de microbialitos proterozoicos abre portas para acessarmos informações fundamentais sobre a paleobiologia e aspectos ambientais pretéritos, além de permitir entender a evolução da (bio)sedimentação carbonática ao longo do tempo geológico (Grotzinger \& Knoll, 1999).

No Brasil, microbialitos foram reconhecidos em vinte e quatro unidades litoestratigráficas distribuídas em quase todo o território nacional (Fairchild \& Sanchez, 2015) e cujas idades vão desde 2,4 Ga (Supergrupo Minas, em MG) até o Holoceno (Região dos Lagos, RJ). Das quatro categorias de microbialitos diferenciadas por Riding (2011), as quais consistem em estromatólitos, trombólitos, dendrólitos e leiólitos, os estromatólitos figuram entre os microbialitos mais reconhecidos no Brasil até o momento (Fairchild \& Sanchez, 2015). Trombólitos, por outro lado, são pouco conhecidos, tendo sido encontrados nos calcários da Formação Sete Lagoas (Warren et al. 2014), da Formação Salitre (GuerraSommer et al., 1993) e na região dos Lagos, no estado do Rio de Janeiro, em sedimentos holocênicos (Vasconcelos \& Bahniuk, 2015). Dendrólitos e leiólitos ainda não foram encontrados no Brasil.

Uma das unidades brasileiras que mais reúne microbialitos é o Grupo Bambuí, que ocorre ao longo dos estados de Minas Gerais, Goiás, Tocantins e Bahia, e consiste na principal cobertura sedimentar aflorante do Cráton do São Francisco (Alkmim \& Martins-Neto 2001; Atman, 2011). Esta sucessão sedimentar vem sendo foco de intenso debate científico ao longo dos últimos anos, especialmente no que tange a sua idade e evolução tectono-sedimentar, paleobiológica e paleoambiental. Embora alguns autores interpretem o Grupo Bambuí como parte do registro de uma bacia marinha dominantemente intracratônica e desenvolvida ao longo do Criogeniano-Ediacarano (e.g. Zalán \& Romeiro-Silva, 2007), seu conteúdo fossilífero (Warren et al., 2014), estudos de proveniência sedimentar (Paula-Santos et al., 2015) e seu arranjo tectono-estratigráfico têm apontado para uma bacia marinha de antepaís, desenvolvida no limite EdiacaranoCambriano, durante a amalgamação do Supercontinente Gondwana Ocidental (e.g. Alkmim \& Martins-Neto, 2001; Martins-Neto, 2009; Reis et al., 2017b).

Sob o ponto de vista litoestratigráfico, o Grupo Bambuí reúne dez formações (e.g. Costa \& Branco, 1961; Dardenne, 1981; Kuchenbecker et al., 2016), sendo três predominantemente carbonáticas. Dentre elas, a Formação Sete Lagoas, em sua base, apresenta 14 morfotipos microbialíticos dispersos por toda a unidade nos estados de Minas Gerais e Goiás, e que são importantes por representarem a recuperação ecológica após evento glacial no Neoproterozoico tardio (ver discussões em Santos et al., 2004; Vieira et al., 2007; Kuchenbecker et al., 2016). Warren e colaboradores (2014) demonstraram a ocorrência de trombólitos associados a conchas de Cloudina, em amostras da Formação Sete Lagoas coletadas na região de Januária, norte de Minas Gerais. Microbialitos também foram identificados na Formação Lagoa do Jacaré, na porção intermediária do grupo em afloramentos nas regiões de Presidente Olegário (Fragoso et al., 2011), São João da Ponte (Iglesias \& Uhlein, 2009), Bom Despacho (Ribeiro et al., 2008), Abaeté (Signorelli, 2009) e Luz (Kuchenbecker $\&$ Pedrosa-Soares, 2010), e recém-analisados em detalhe por Santos (2018). Já na Formação Jaíba, na porção superior do Grupo Bambuí, estromatólitos e trombólitos foram relatados por Chiavegatto e colaboradores (2003), Atman (2011) e Kuchenbecker et al. (2014), porém, permanecem sem estudo.

O termo trombólito foi cunhado em 1967 por Aitken, a partir do registro sedimentar cambro-ordoviciano do oeste do Canadá. São caracterizados por não apresentarem laminações internas (tal como os estromatólitos) e, sim, estruturas semelhantes a coágulos, conhecidas como grumos, observáveis tanto em escala macroscópica como mesoscópica (Riding, 2011). A ocorrência de trombólitos no Grupo Bambuí é de particular importância, uma vez que estas formas tornaram-se abundantes no Cambriano, provavelmente em face à diversificação de metazoários e, por consequência, a predação de esteiras microbianas (Awramik, 1971; Riding, 2006).

Neste trabalho, são analisados microbialitos pertencentes à Formação Jaíba, Grupo Bambuí. Analisam-se aqui níveis de laminitos microbianos e trombólitos, anteriormente relatados (Chiavegatto et al., 2003; Atman, 2011; Kuchenbecker et al., 2014), com ênfase em seus aspectos microscópicos. Além de trazer contribuições sobre a paleobiologia do Grupo Bambuí, o presente trabalho traz uma análise inédita dos trombólitos ainda pouco conhecidos nesta unidade e que podem revelar importantes elementos para o entendimento de aspectos paleoecológicos da transição entre o Ediacarano e o Cambriano. Os resultados obtidos neste estudo, juntamente com os demais estudos disponíveis na literatura (e.g. Sanchez 2014, Fantinel et al., 2015), podem representar ainda uma importante contribuição para o avanço do entendimento peleoambiental de bacias de antepaís antigas. 


\section{CONTEXTO GEOLÓGICO}

A área de estudo situa-se na Serra da Jaíba, localizada a cerca de $600 \mathrm{~km}$ de Belo Horizonte, no município de Verdelândia, norte do estado de Minas Gerais. Nesta região afloram rochas pertencentes ao Grupo Bambuí (Figura 1), uma das mais importantes coberturas sedimentares da porção sul do Cráton do São Francisco, ocorrendo por cerca de $350.000 \mathrm{~km}^{2}$ nos estados de Minas Gerais, Bahia, Goiás e Tocantins (Atman, 2011). Conforme diversos autores (e.g. Alkmim \& Martins-Neto, 2001; Martins-Neto, 2009; Kuchenbecker, 2014; Reis \& Suss, 2016), as rochas do Grupo Bambuí registram o preenchimento de uma extensa bacia de antepaís, desenvolvida sobre o paleocontinente São Francisco, sobretudo, em resposta à edificação diacrônica dos orógenos Brasília (a oeste) e Araçuaí (a leste) entre o fim do Neoproterozoico e o início do Paleozoico. O arranjo estratigráfico do Grupo Bambuí define ao menos quatro ciclos transgressivo-regressivos, contínuos ao longo de grande parte da bacia homônima (e.g. Martins \& Lemos, 2007; Reis \& Suss, 2016). Tais ciclos sedimentares incluem os depósitos das formações Carrancas (conglomerado, siltito, dolomito), Sete Lagoas (dominantemente rochas carbonáticas), Serra de Santa Helena (siltito, arenito fino e rochas carbonáticas restritas), Lagoa do Jacaré (dominantemente rochas carbonáticas), Serra da Saudade (siltito e arenito fino, com intercalações de calcários) e Três Marias (arenito, pelito e ruditos subordinados). Ocorrendo extensamente ao longo dos setores leste e central da bacia, estas formações representam as unidades clássicas do Grupo Bambuí (e.g. Costa e Branco, 1961; Dardenne, 1978; 1981). Enquanto as rochas sedimentares da Formação Carrancas incluem unidades pósglaciais depositadas após um importante evento climático do fim do Neoproterozoico (e.g. Kuchenbecker et al., 2013b; Uhlein et al., 2016; Reis et al., 2017b), as demais registram uma sedimentação mista siliciclástica-carbonática em
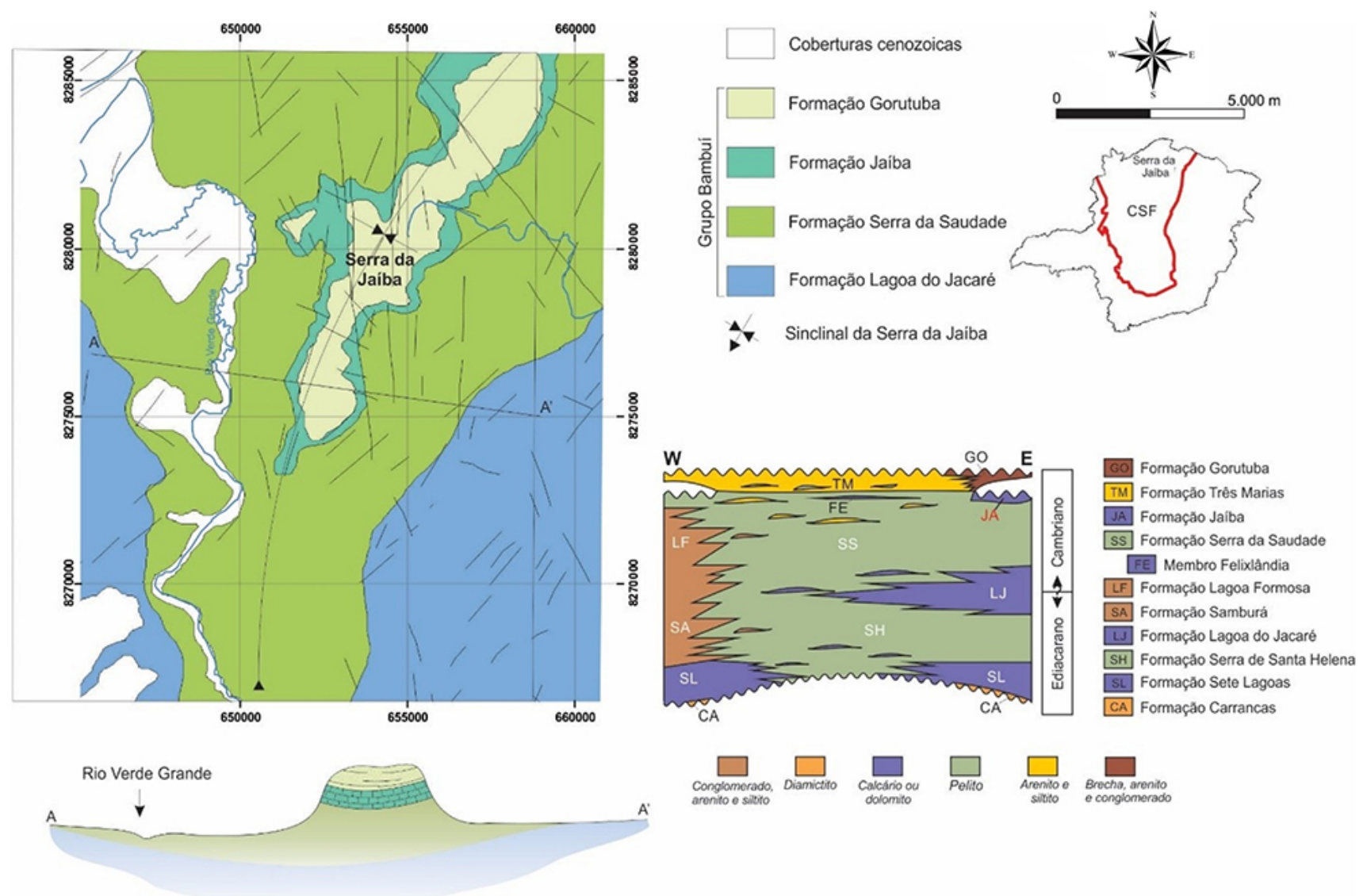

Figura 1. Formação Jaíba na Serra da Jaíba, em Verdelândia, MG. Mapa geológico modificado de Kuchenbecker et al. (2013a) e diagrama estratigráfico de Kuchenbecker et al. (2016). Localização da Serra da Jaíba no estado de Minas Gerais. Traço vermelho corresponde ao limite do Cráton do São Francisco, segundo Alkmin (2004). O diagrama estratigráfico da Bacia do Bambuí está representado pelas suas principais unidades de preenchimento da bacia em Minas Gerais, dando destaque para a situação estratigráfica da Formação Jaíba.

Figure 1. Jaíba Formation at the Jaíba Hills, in Verdelândia, MG. Geological map modified from Kuchenbecker et al. (2013a) and stratigraphic diagram from Kuchenbecker et al. (2016). Localization of Jaíba Hills in the state of Minas Gerais. Red trace corresponds to the limit of São Francisco Craton, according to Alkmin (2004). Stratigraphic diagram of Bambuí Basin is represented by its main units in the State of Minas Gerais, highlighting the stratigraphic context of Jaíba Formation. 
ambiente dominantemente marinho plataformal e relacionado a baixas taxas de subsidência (e.g. Martins \& Lemos, 2007; Reis et al., 2017a).

Junto à borda oeste da Bacia Bambuí, as formações Samburá (rudito, pelito e arenito) e Lagoa Formosa (rudito, siltito) representam grandes cunhas clásticas de foredeep, relacionadas ao avanço das frentes de empurrão da Faixa Brasília (Castro \& Dardenne, 2000; Uhlein et al., 2017). As formações Jaíba (calcário) e Gorutuba (brecha siliciclástica, arenito, conglomerado), por outro lado, ocorrem exclusivamente na borda leste da bacia, tendo a Serra da Jaíba - área de estudo deste trabalho - como um de seus principais locais de ocorrência (e.g. Chiavegatto et al., 2003; Kuchenbecker et al., 2016).

A idade das rochas do Grupo Bambuí tem sido alvo de intenso debate científico nas últimas décadas (e.g. Babinski et al., 2007; Rodrigues, 2008; Pimentel et al., 2011; Caxito et al., 2012; Paula Santos et al., 2015). A descoberta de fósseis do gênero Cloudina em calcários da Formação Sete Lagoas (Warren et al., 2014), aliada à presença de zircões detríticos de c. $550 \mathrm{Ma}$ em rochas da mesma unidade (Paula-Santos et al., 2015), indicam que o desenvolvimento da Bacia Bambuí teve início no Ediacarano tardio-início do Cambriano.

A Serra da Jaíba representa a expressão geomórfica de um sinclinal suave e é sustentada em sua base por siltitos da Formação Serra da Saudade que, para o topo, passam gradativamente para as rochas dominantemente carbonáticas da Formação Jaíba (Kuchenbecker et al., 2013a). A Formação Jaíba é uma sucessão de aproximadamente 40 metros de espessura, formada principalmente por calcilutito cinza claro, com lâminas argilosas de espessura milimétrica. Subordinadamente ocorrem calcilutitos com laminação microbiana e porções calcareníticas (e.g. Chiavegatto et al., 2003; Atman, 2011; Kuchenbecker et al.; 2013b). No topo da serra, a Formação Jaíba é recoberta discordantemente pela Formação Gorutuba. A discordância erosiva registrada no contato entre as unidades é materializada por um espesso pacote de brecha de matriz arcoseana e clastos angulosos de calcário que, para o topo, dão lugar a arenitos e conglomerados. Estas rochas representam os últimos registros conhecidos dos ambientes transicionais e continentais desenvolvidos na borda leste da Bacia Bambuí (Kuchenbecker et. al., 2016).

\section{MATERIAL E MÉTODOS}

O afloramento estudado $\left(15^{\circ} 36^{\prime} 29.84^{\prime \prime} \mathrm{S} / 4^{\circ} 35^{\prime} 16.26^{\prime \prime O}\right)$ está localizado na Serra da Jaíba, próximo à cidade de Verdelândia, em uma trilha acessada a partir da rodovia MG-401, no norte do Estado de Minas Gerais. As primeiras análises foram realizadas em campo, em escala mega- e macroscópica (Hofmann, 1969), seguindo os parâmetros propostos por Fairchild \& Sanchez (2015). Foram coletadas amostras de microbialitos e rochas associadas, as quais foram incorporadas à coleção científica de fósseis do Laboratório de Paleontologia do Centro de Estudos em Geociências da Universidade Federal dos Vales do Jequitinhonha e Mucuri (LabPaleo/CeGeo/UFVJM), sob os códigos C.MBL-14 a 26. As amostras coletadas para a realização de análises na escala de mão, portanto, mesoscópica (Hofmann, 1969) foram observadas em estereomicroscópio WF 10X/23 da marca Nova Optical System, no Laboratório de Mineralogia (LabMin/CeGeo), observando-se os parâmetros propostos por Fairchild \& Sanchez (2015).

Por fim, sete lâminas petrográficas foram confeccionadas no Laboratório de Laminação do CeGeo/UFVJM e descritas em microscópio petrográfico da marca Zeiss ${ }^{\circledR}$, modelo Axio Lab.A1. no Laboratório de Microscopia do CeGeo/UFVJM. A classificação de texturas e estruturas microbialíticas seguiram a classificação de Duham (1962) e Sanchez (2014). As lâminas petrográficas encontram-se tombadas no laminário do LabPaleo/CeGeo/UFVJM, sob os códigos C.LAM-10 a C.LAM-16.

\section{RESULTADOS}

Os dois tipos de microbialitos identificados em campo consistem em laminitos microbianos e trombólitos. Eles ocorrem em estratos distintos do afloramento, sendo o nível trombolítico restrito, mal preservado (Figura 2A), intercalado em rochas carbonáticas com estratificações cruzadas do tipo hummocky e subjacente à ocorrência de laminitos. Os laminitos microbianos ocorrem poucos metros estratigraficamente acima dos trombólitos, apresentam-se bem preservados, destacados pela ação intempérica ou em cortes frescos (Figura 2C). Ocorrem em ampla área em meio a espessos níveis de calcarenitos cinza claro deformados e intercalados com laminações de material terrígeno pelítico (Figura 2B). Estes níveis tornam difícil a distinção entre laminações biogênicas e abiogênicas, mesmo em escala macrométrica.

Os trombólitos podem ser vistos em corte oblíquo ao plano de acamamento. Apresentam-se como estruturas contíguas, ou seja, muito próximas umas às outras, de formato irregular, alongado ou elíptico, todas com bordas arredondadas e tamanho centimétrico. Destacam-se pela diferença de cor da rocha encaixante, pois estes microbialitos são de cor cinza médio, enquanto que a rocha encaixante tem cor cinza claro. Em raros pontos é possível ver coalescência, mesmo estando em planta (Figuras 2A, 3A). Uma vez que trombólitos não apresentam laminação e sim macrotextura aglutinante, poucos caracteres puderam ser reconhecidos (Figura 3B). Por outro lado, a análise microscópica permitiu o detalhamento de duas microtexturas, microfósseis e estruturas relacionadas à diagênese e anquimetamorfismo.

Observou-se que tanto os trombólitos, quanto o carbonato da rocha encaixante, são compostos de micrita maciça (Figura 3C), diferenciando-se apenas pela cor. A exemplo do observado em macroescala, os trombólitos apresentam cor mais escura (cinza muito escuro) enquanto que o material intertrombolítico é mais claro. A outra microtextura foi identificada no contato entre estas duas áreas (Figura 3C). As bordas do trombólitos são marcadas por microtextura micrítica, porém, rica em fenestras pequenas, irregulares e distribuídas sem orientação preferencial. 
Associados às estruturas trombolíticas foram identificados microfósseis filamentosos. Trata-se de estruturas tubulares (Figura 3D), eretas, densamente empacotadas, com parede de uma camada só e lúmen vazio. Apresentam extensão maior que $100 \mu \mathrm{m}$ e diâmetros menores que $10 \mu \mathrm{m}$. Exibem crescimento em diferentes sentidos, não apresentando um ponto distinto de início do crescimento dos filamentos.
Os laminitos apresentam laminações delgadas com relevos sinópticos que variam entre plano, ondulado e crenulado em mesoescala (Figuras 4A-B). Podem ser planas ou apresentam curvatura em aspecto abobadado, o que confere dois graus de curvatura aos laminitos. Pontualmente o relevo sinóptico torna-se expressivo, dando origem a pseudocolunas centimétricas (Figuras 4C-D) eretas, verticais, simétricas e com alta herança laminar.

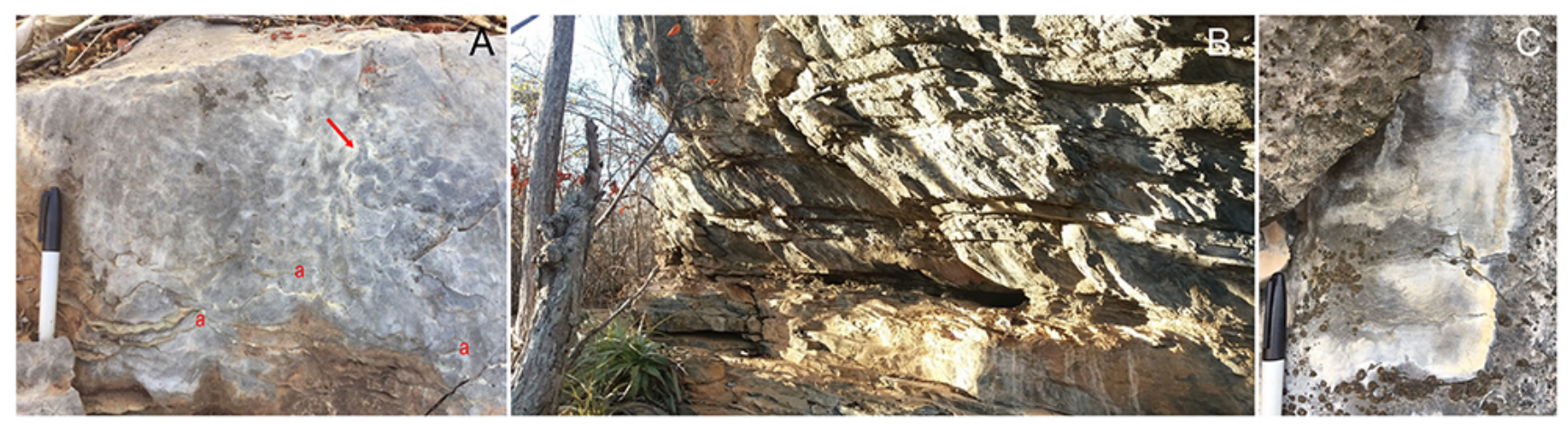

Figura 2. Níveis fossilíferos da Formação Jaíba, na serra homônima, em Verdelândia, MG. A, ocorrência de trombólitos em corpo carbonático. Notar variedade de formas. Seta indica forma coalescente. B, níveis de calcarenitos cinza claro espessos, que intercalam com laminações de material terrígeno. Laminitos ocorrem pontualmente nesses níveis. $\mathbf{C}$, ocorrência de laminito microbiano visto em corte de rocha fresca.

Figure 2. Fossiliferous outcrops of Jaíba Formation, in the homonymous hills, at Verdelândia, MG. A, thrombolite occurrence in a carbonatic level. Note variation in thrombolitic shapes. Arrow indicates coalescent column. B, thick light gray calcarenites beds, intercalated with lamination of terrigenous material. Laminites show restricted occurrence in these beds. $\mathbf{C}$, laminate occurrence in a rock fresh cut.

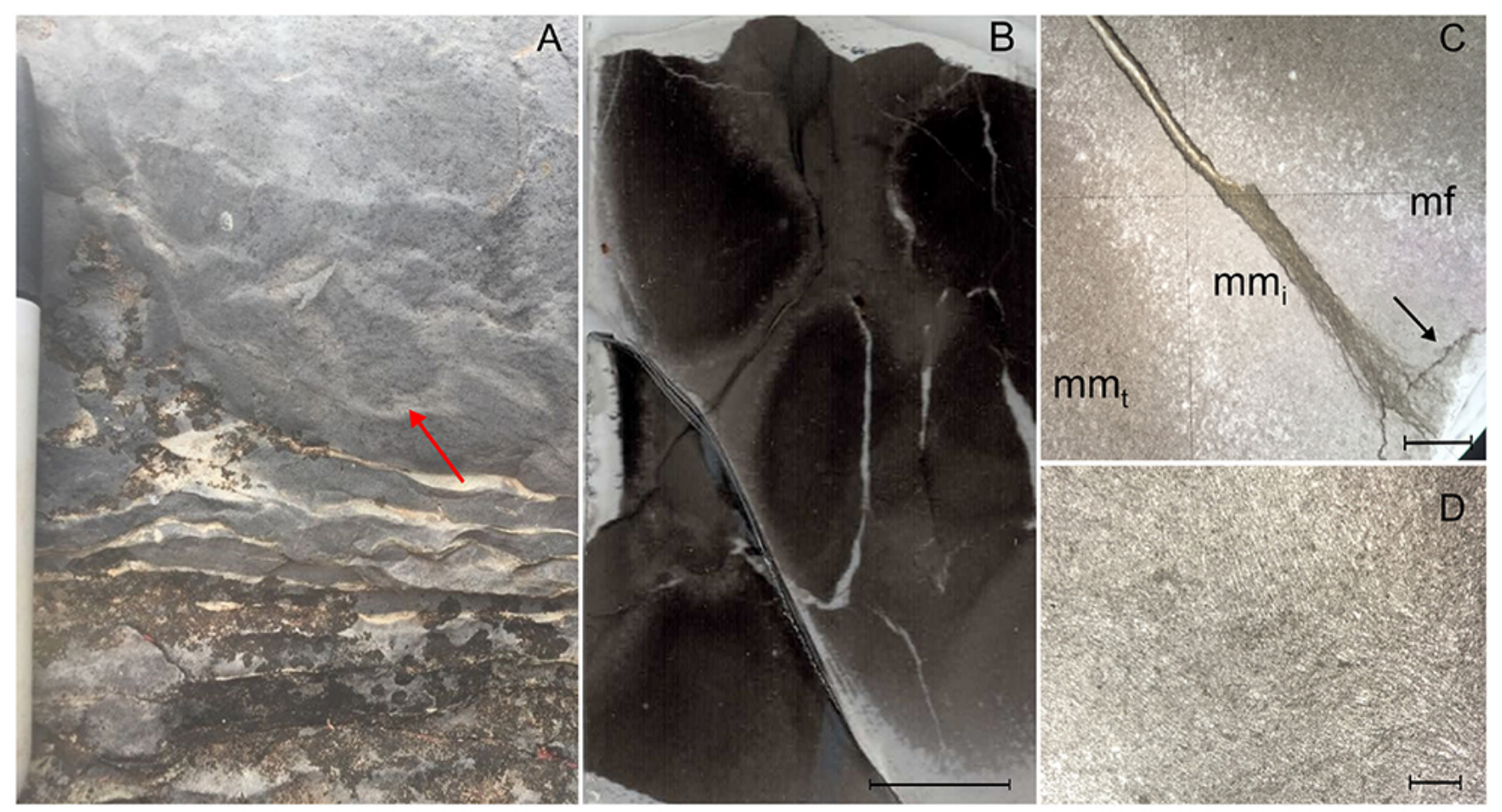

Figura 3. Aspectos dos trombólitos da Formação Jaíba. A, colunas trombolíticas com formas variadas. Notar coluna coalescente (seta vermelha). B, trombólitos vistos em mesoescala demosntrando aspecto maciço e homogêneo. Partes escuras correspondem à porção trombolítica. $\mathbf{C}$, microtexturas identificadas nas amostras de trombólitos. Os códigos mmi, mmt e mf correspondem, respectivamente, à textura micrítica maciça intercolunar, micrítica maciça trombolítica e micrítica fenestrada. D, microfósseis filamentosos encontrados associados aos trombólitos. Notar parede simples. Escalas: $\mathrm{B}=1 \mathrm{~cm} ; \mathrm{C}-\mathrm{D}=500 \mu \mathrm{m}$.

Figure 3. Aspects of thrombolites from Jaíba Formation. A, thrombolitic columns showing different morphologies. Note columnar coalescent (red arrow). B, thrombolites in mesoscale showing massive homogeneous aspect. Dark areas correspond to thrombolites. C, microfabrics identified in thrombolitic samples. The codes mmi, mmt and $\mathrm{mf}$ corresponds, respectively, to intercolumnar massive micritic, thromobolitic massive micrita and fenestrae micrita. D, filamentous microfossils associated to thrombolites. Note simple wall. Scale bars: B $=1 \mathrm{~cm} ; \mathrm{C}-\mathrm{D}=500 \mu \mathrm{m}$. 
A

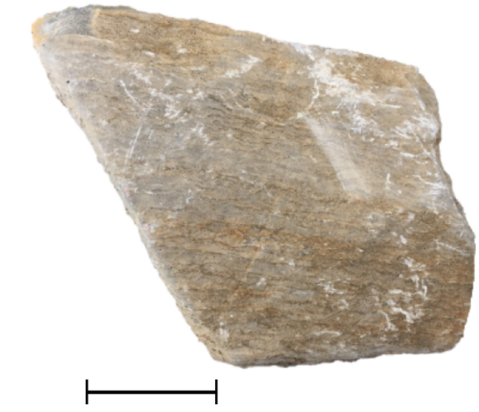

B

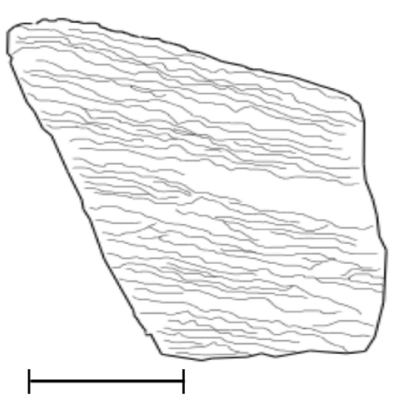

C

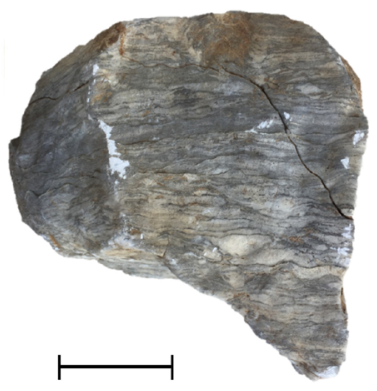

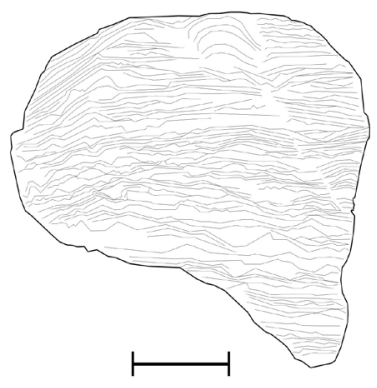
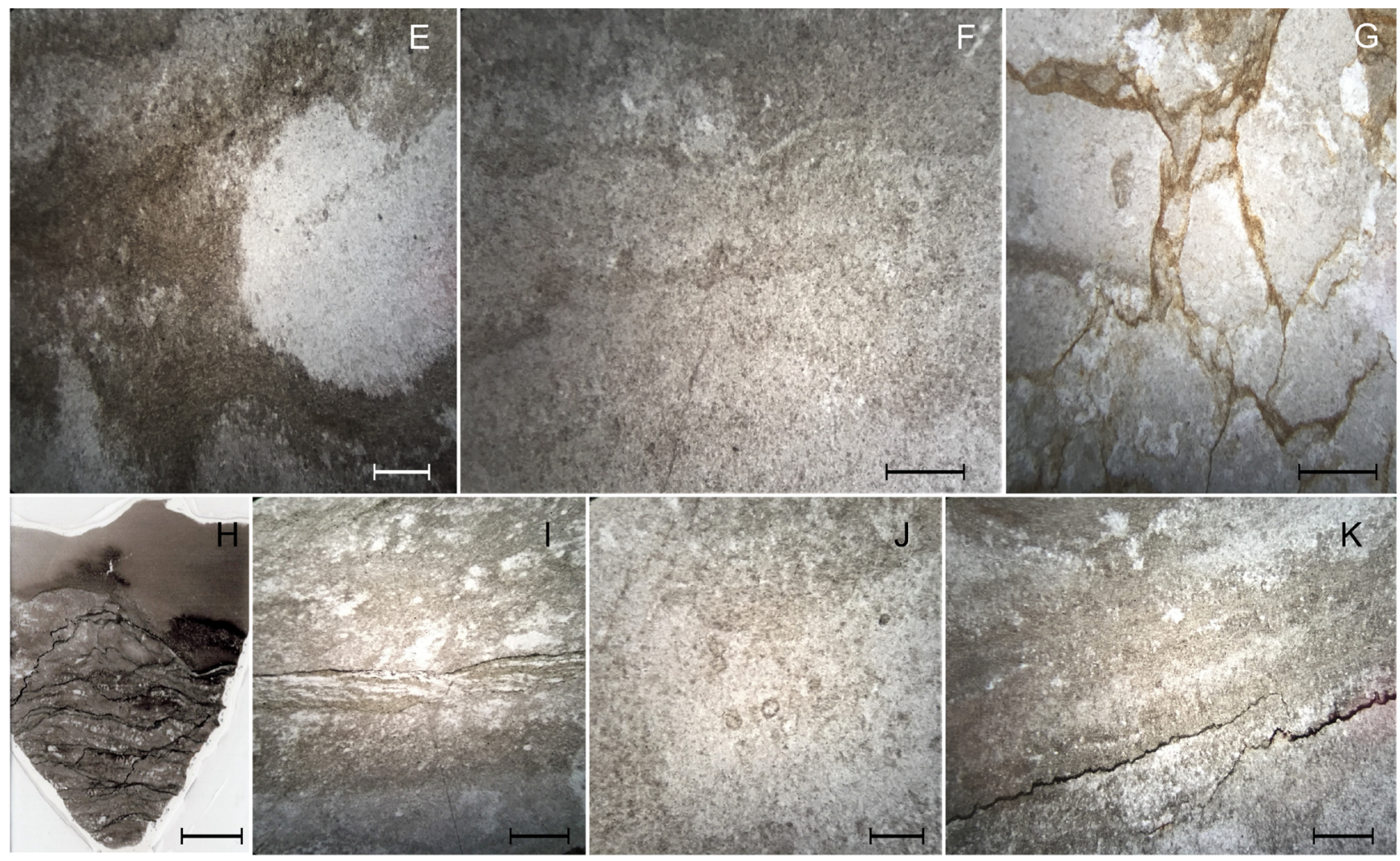

Figure 4. Aspectos dos laminitos da Formação Jaíba. A-D, exemplo de amostras carbonáticas ricas em níveis de argila às quais os laminitos ocorrem associados. Notar em C e D a pseudocoluna que se desenvolveu no topo da amostra. E-G, microtextura mosqueada composta pela interação entre zonas de micrita (áreas escuras) e peloides (áreas claras) em E, ou interação entre zonas de micrita clara e escura em F, e associada à rede de estilólitos em G. H, alternância de microtextura peloidal (base da amostra) e micrítica maciça (topo da amostra) na escala centimétrica. I, alternância entre microtexturas mosqueada e peloidal, altamente fenestrada. $\mathbf{J}$, microfósseis cocoides isolados, que ocorrem associados à microtextura micrítica. $\mathbf{K}$, Alternância de microtexturas peloidal e mosqueada, demonstrando forte foliação, que conferiu padrão estirado a todos os componentes. O mesmo pode ser notado em E. Escalas: A-D = 2 cm; E $=250 \mu \mathrm{m} ; \mathrm{F}-\mathrm{G}, \mathrm{I}, \mathrm{K}=1 \mathrm{~mm} ; \mathrm{H}=5 \mathrm{~mm} ; \mathrm{J}=500 \mu \mathrm{m}$.

Figure 4. Aspects of laminites from Jaíba Formation. A-D, examples of hand samples composed by rich-mud carbonate to which laminites occur associated. Note in $\mathrm{C}$ and $\mathrm{D}$ the occurrence of pseudocolumnar stromatolite at the top of the sample. $\mathbf{E}-\mathbf{G}$, mottled microfabric composed by the interaction between micritic zones (dark areas) and peloids (light areas) in E, or interaction between dark and light micritic zones in F, or associated to a net composed by stylolites in G. H, alternation between peloidal microfabric (base of the sample) and massive micritic (top of the sample) in centimetric scale. I, alternation between mottled and peloidal microfabrics, with abundant fenestrae. $\mathbf{J}$, isolated coccoidal microfossils associated to massive micritic microfabric. $\mathbf{K}$, alternation between mottled and peloidal microfabrics showing strong foliation that imposed a stretched foliation to all components. The same situation can be seen in E. Scales: A-D = $2 \mathrm{~cm} ; \mathrm{E}=250 \mu \mathrm{m} ; \mathrm{F}-\mathrm{G}, \mathrm{I}, \mathrm{K}=1 \mathrm{~mm} ; \mathrm{H}=5 \mathrm{~mm} ; \mathrm{J}=500 \mu \mathrm{m}$.

Em escala microscópica, os laminitos apresentaram três microtexturas, todas incluindo porções de micrita clara, micrita escura e porções peloidais. A primeira microtextura consiste da interação entre manchas de micrita clara e micrita escura, porém, raramente ocorrem porções de peloides. Estas manchas apresentam bordas arredondadas e estão dispostas em mosaico. Por esta razão, esta textura é aqui tratada como microtextura mosqueada (Figuras $4 \mathrm{E}-\mathrm{F}$ ). Algumas amostras são compostas de uma variante desta microtextura. Neste caso, o limite entre as manchas de micrita clara, micrita escura $\mathrm{e}$ 
peloides está fortemente demarcado por material escuro, o que, em primeira análise levou à interpretação de se tratar de uma brecha intraclástica. Porém, utilizando-se contrastes diferentes, identificou-se que o material escuro compreende resíduo insolúvel de processos de dissolução relacionados à estilolitização (Figura 4G).

As outras duas microtexturas observadas são maciças e formadas por componentes primários e diagenéticos. Uma delas consiste de micrita maciça eventualmente microfossilífera, enquanto que a outra consiste de packstone composto de peloides mal preservados, rica em fenestras e associadas a finas laminações de material terrígeno. Estas duas texturas se alternam em algumas amostras, em escalas que variam de centimétrica (Figura $4 \mathrm{H}$ ) a submilimétrica. Também ocorreram associadas à microtextura mosqueada, alternando com esta em escala submilimétrica (Figura 4I) e formando laminações onduladas.

Microfósseis foram identificados associados à microtextura micrítica. Trata-se de formas cocoidais, que variam de 20 a $100 \mu \mathrm{m}$ de diâmetro, e que podem ocorrer densamente empacotados até frouxamente empacotados, porém sempre aglutinados.

Apesar das rochas encontrarem-se afetadas por uma clivagem conspícua de direção NNE-SSW, as estruturas primárias foram preservadas. Nos laminitos, estas estruturas se manifestam através do achatamento e orientação generalizada dos elementos primários (Figura 4K).

\section{DISCUSSÃO}

A análise do registro fóssil da Formação Jaíba consiste, até o momento, de microbialitos estromatolíticos do tipo laminitos e trombólitos. Trata-se de uma nova ocorrência de microbialitos no Grupo Bambuí, somando-se a aquelas da Formação Sete Lagoas (e.g. Sanchez, 2014; Fantinel et al., 2015), na base do grupo, e da Formação Lagoa do Jacaré (e.g. Fragoso et al., 2011; Santos, 2018), na sua porção intermediária. Conforme dados disponíveis na literatura (e.g. Reis \& Suss, 2016; Kuchenbecker et al., 2016), as ocorrências de microbialitos na Formação Jaíba constituem parte do registro de uma das últimas plataformas carbonáticas e mistas desenvolvidas durante a sedimentação do Grupo Bambuí.

Apesar da má qualidade de preservação dos trombólitos aqui identificados, foi possível observar formas colunares e irregulares centimétricas e pontualmente coalescentes. Os padrões morfológicos são semelhantes ao reconhecido em trombólitos de outras unidades cronocorrelatas, tal como os trombólitos neoproterozoicos de Noonday Dolomite, nos Estados Unidos (Corsetti \& Grotzinger, 2005), as formas associadas a Namacalathus no Grupo Nama, na Namíbia (Grotzinger et al., 2000), e os trombólitos cambrianos das formações Notch Peak e Nopah, ambas nos Estados Unidos (Shapiro, 2000; Coulson, 2016). Na escala de bacia sedimentar, no entanto, a identificação de trombólitos com estas características é inédita, uma vez que apenas trombólitos dômicos haviam sido descritos na Formação Sete Lagoas (Warren et al., 2014).
Ocorrendo associados a uma sucessão monótona de calcarenitos finos com estratificações cruzadas do tipo hummocky de porte até métrico, os trombólitos identificados neste trabalho parecem ter se desenvolvido em uma plataforma carbonática influenciada por ondas de tempestade. Neste contexto, tais características, combinadas à ausência de elementos diagnósticos do retrabalhamento por ondas de bom tempo e exposição, sugerem ambientes de submaré. Entretanto, levantamentos adicionais são necessários para melhor avaliar sua posição ao longo da plataforma carbonática estudada. Trombólitos já foram encontrados em áreas de submaré nas margens de plataforma (Braga et al., 1995; Grotzinger et al., 2000; Whalen et al., 2002), porém, formas desenvolvidas em ambientes de inter a supramaré parecem ser as mais comuns (Walter \& Heys, 1985).

A análise petrográfica deste material revelou microtexturas monótonas, constituídas de micrita maciça ou níveis micríticos fenestrados. Este padrão não está de acordo com o esperado para trombólitos, uma vez que este tipo de microbialito apresenta tipicamente microtextura grumosa, composta por peloides, algas calcificadas e cimento (Shapiro, 2000; Turner et al., 2000). No entanto, trombólitos como aqueles da Formação Timna, em Israel, de idade cambriana, são formados por micrita, e apresentam preservação palimpséstica de peloides, além de, a exemplo das formas descritas neste trabalho, fenestras (Soudry \& Weissbrod, 1995). Argumenta-se aqui que os trombólitos da Formação Jaíba podem representar duas situações excludentes: (i) os trombólitos da Formação Jaíba preservam um novo tipo de microtextura, essencialmente micrítica, ainda não reconhecida em outros trombólitos; ou (ii) não apresentam peloides em sua microtextura por uma questão tafonômica, em que o material original teria sido micritizado em virtude de processos diagenéticos e aquimetamórficos que afetaram esta unidade.

As duas hipóteses apresentam argumentos prós e contras. No caso da primeira hipótese, ou seja, de que o aspecto micrítico é primário, a micrita seria o resultado da deposição de material carbonático detrítico fino (calcilutito) associado à micrita precipitada pelo metabolismo da biota formadora do trombólitos (Flüguel, 2010).

Turner et al. (2000) realizaram uma análise profunda da microtextura de trombólitos pré-edicaranos da Formação Little Dal, no oeste do Canadá. Os autores demonstraram a influência da tafonomia sobre os componentes observados, o que traz um forte viés sobre a interpretação do modo de crescimento destes microbialitos. Neste mesmo trabalho, os autores relataram que áreas ricas em micrita, laminadas ou não, podem estar associadas lateralmente a áreas com ocorrência de microfósseis filamentosos. Turner e seus colaboradores propuseram que este estilo de ocorrência de micrita seria resultado da compactação e outros processos tafonômicos que afetaram os microorganismos filamentosos que compunham os trombólitos da Formação Little Dal. Na Formação Jaíba, as áreas micríticas e microfossilíferas não intergradam lateralmente, mas estão em colunas trombolíticas diferentes. No entanto, a explicação tafonômica para a 
presença de micrita, indo na contramão do que se conhece para a microtextura de trombólitos, pode ser aplicado neste caso do Grupo Bambuí.

Outra explicação para a ausência de peloides pode estar nos processos de micritização. Estes são processos impostos durante a fase de diagênese, que levam à homogeneização do carbonato e consequente perda dos peloides (ver discussão em MacIntyre \& Reid, 1978). No entanto, como os efeitos dos processos tafonômicos em microbialitos são ainda pouco conhecidos (Turner et al., 2000), não se pode atribuir, com segurança, a ausência de peloides nos trombólitos da Formação Jaíba à micritização. Apesar de as feições observadas serem indícios promissores de uma nova textura trombolítica, a confirmação desta hipótese necessitará de estudos mais abrangentes, com amostragem mais ampla.

Microfósseis filamentosos foram encontrados nos trombólitos da Formação Jaíba, demonstrando que o material original permanece, embora mal preservado. Esta característica suporta a hipótese de que a microtextura micrítica é primária. O terceiro ponto que suporta o caráter primário da microtextura micrítica, e que anula a hipótese de que a micrita seria resultado de processos tafonômicos que degradaram totalmente os peloides, é a preservação de peloides nos laminitos sobrejacentes aos trombólitos, a despeito dos processos pós-deposicionais a que a Formação Jaíba, como um todo, foi submetida.

No que tange a biogenicidade dos fósseis filamentosos da Formação Jaíba, é necessário remeter-se ao trabalho clássico de Buick (1991), em que o autor enumerou caracteres que devem ser observados em estruturas dúbias, a fim de constatar sua biogenicidade. Das sete características propostas por Buick, os microfósseis filamentosos atendem a cinco delas, uma vez que: (i) ocorrem em lâmina petrográfica; (ii) o objeto ocorre em rocha sedimentar ou rocha com baixo grau de metamorfismo; (iii) o objeto é maior que o menor ser vivo conhecido, já que apresenta vários micrometros de comprimento; (iv) o objeto ocorre juntamente com outras formas similares, uma vez que foi encontrada uma colônia ou aglomerado destes microfósseis; e (v) o objeto é vazio, caractere este comprovado pela observação do lúmen. Os únicos quesitos que não foram contemplados é a composição química, não analisada, e a elaboração celular, não observada. No caso da Formação Jaíba, trata-se de microfósseis tubulares vazios, sem a ocorrência de células (tricomas) preservados, associados a trombólitos.

Uma possível interpretação destes microfósseis tubulares como leques de aragonita anularia sua interpretação biogênica. No entanto, leques de aragonita são estruturas geopetais, que se desenvolvem eretas, mostrando o topo da sucessão. Além disso, não apresentam lúmen e seu ponto inicial de nucleação é facilmente identificável (Flüguel, 2010). Estes três aspectos não são observados no caso das estruturas aqui interpretadas como microfósseis, uma vez que apresentaram crescimentos em diferentes direções, são ocas e seu lúmen pode ser observado, bem como o ponto inicial de crescimento não pode ser identificado. Portanto, interpreta-se aqui estas estruturas tubulares como microfósseis filamentosos.
Os laminitos da Formação Jaíba foram reconhecidos em escala macro e mesoscópica. Laminações onduladas, com alternância de lâminas claras e escuras, foram classificadas como microbialíticas. Nestas amostras, três microtexturas foram identificadas. A microtextura predominante é aquela formada por peloides, rica em fenestras primárias e secundárias, e cujos grãos estão mal preservados. Subordinadamente, ocorrem as microtexturas mosqueada e micrítica, esta com ocorrência de microfósseis. Estes padrões já foram identificados e revelaram-se ser os mais comuns nos microbialitos da Formação Sete Lagoas (Sanchez, 2014). O padrão peloidal foi encontrado associado a quatro formas estromatolíticas em nove localidades. O padrão micrítico foi encontrado associado a cinco morfotipos de estromatólitos em cinco localidades sobre o Cráton do São Francisco. Já a microtextura mosqueada, então nomeada micrítica fenestrada, ocorre associada a estromatólitos colunares, ramificados ou não, e laminitos (Sanchez, 2014).

As tramas peloidais são interpretadas aqui como exclusivamente formadas por processos abiogênicos, uma vez que os peloides seriam o resultado do processo de micritização de outros grãos carbonáticos (Flüguel, 2010) em áreas plataformais rasas. Desta forma, sua presença associada a laminitos estaria relacionada à deposição de grãos carbonáticos sobre as esteiras microbianas e posterior ocorrência de processos diagenéticos. Embora uma origem biogênica, relacionada à calcificação de células procarióticas (Défrage et al., 1996; Flüguel, 2010) não possa ser descartada, os peloides da Formação Jaíba não apresentam variação na forma, ocorrem dispersos na matriz carbonática e apresentam tamanho homogêneo, sugerindo algum tipo de seleção, feições que advogam contra a hipótese de serem moldes ou contramoldes celulares. Formas procarióticas crescem em aglomerados ou colônias e ambos podem ser preservados, assim como células individuais (ver discussão em Knoll \& Golubic, 1979) e posteriormente calcificar. Desta forma, é esperado que a calcificação e consequente formação de peloides a partir de colônias de formas cocoides apresentem variação de tamanho e forma entre os "grãos" (Flüguel, 2010). Como esta situação não foi observada nos laminitos da Formação Jaíba, postula-se aqui que são de origem abiogênica, tratando-se da micritização de grãos carbonáticos.

As microtexturas micrítica e mosqueadas, por outro lado, são aqui interpretadas como resultantes do crescimento microbiano e posterior compactação da micrita restante. Carbonatos apresentam grande afinidade com matéria orgânica amorfa, usando-a como sítio de nucleação (Défrage et al., 1996; Bartley et al., 2000). Durante a litificação de esteiras microbianas, há grande abundância de sítios disponíveis para nucleação na matéria orgânica em vias de decomposição. Isto resulta na precipitação rápida de carbonato, mas limita o espaço disponível para o crescimento dos cristais. $O$ resultado são matrizes minerais compostas por cristais diminutos, subédricos a anédricos, do tipo micrita (Défrage et al., 1996; Bartley et al., 2000; Sanchez, 2014). No entanto, apenas a análise em macro e mesoescala permite 
atribuir aos laminitos origem biogênica, atestada pelo relevo sinóptico das laminações e seu perfil laminar.

Ainda tratando da análise em macro e mesoescala, nota-se que os laminitos ocorrem restritos em vários níveis estratigráficos da Formação Jaíba, porém, quando se desenvolvem, estão restritos a poucos centímetros e não geram qualquer alteração na topografia do substrato. Por estas razões, chega-se à conclusão de que os laminitos agiam como coadjuvantes na sedimentação carbonática da Formação Jaíba, sendo os processos sedimentares abiogênicos os principais responsáveis pela formação das rochas desta unidade.

Os microfósseis descritos - bainhas filamentosas nos trombólitos e invólucros cocoidais nos laminitos - não permitem classificação em espécies paleontológicas (Knoll \& Golubic, 1979), devido à falta de caracteres diagnósticos. Formas filamentosas já foram identificadas em trombólitos neoproterozoicos da Formação Little Dal, no Canadá (Turner et al., 2000), onde são os principais componentes na formação das bioconstruções. Devido à ocorrência pontual, o papel dos filamentos como formadores dos trombólitos da Formação Jaíba permanece incerto.

Quanto às formas cocoidais, por estarem mal preservados acabam se assemelhando a peloides. No entanto, por estarem preservados como aglomerados, eles foram aqui classificados como microfósseis. Outra hipótese para explicar estas estruturas, anulando-se a anterior, seria de que se trata de peloides micritizados. No entanto, quando se trata destes grãos, eles apresentam diferentes tamanhos e distribuição randômica. Neste caso, as estruturas em questão apresentam limites de tamanho condizentes com células e organizam-se em aglomerados, características esperadas para formas unicelulares (ver discussão em Défrage et al., 1996 e Flüguel, 2010).

Indivíduos do gênero Entophysalis são conhecidos por formarem laminitos modernos em uma grande gama de ambientes, desde emersos até em ambiente de submaré, os quais apresentam em comum a baixa taxa de sedimentação e acreção da esteira microbiana muito lenta (Seong Joo et al., 2000). Este pode ser o caso da Formação Jaíba. Embora não seja possível atribuir os microfósseis encontrados nos laminitos ao gênero Eoentophysalis, o análogo fóssil do gênero Entophysalis (Hofmann, 1976), a presença de cocoides indica que o ambiente de deposição desta porção da Formação Jaíba pode ter sido um ambiente calmo e muito raso, a qual levava ao desenvolvimento de fenestras pelo escape de gases (Monty, 1976), além de permitir a deposição dos níveis de argila. Ciclicamente, a energia do ambiente aumentava ainda dentro do tempo de crescimento da esteira, o que permitia a deposição da microtextura de peloides e tornava as esteiras subordinadas no processo de deposição do carbonato.

\section{CONCLUSÕES}

O potencial fossilífero da Formação Jaíba começou a ser explorado no presente trabalho. Dois tipos de microbialitos foram encontrados e compreendem trombólitos e laminitos, desenvolvidos em distintos momentos evolutivos de uma plataforma carbonática influenciada por tempestades. Os trombólitos ocorrem de forma restrita, enquanto que os laminitos ocorrem ao longo de vários metros estratigráficos, em alguns momentos com desenvolvimento expressivo de vários centímetros, porém, na maior parte da sucessão ocorre de forma restrita, apontando para uma participação secundária na deposição dos carbonatos da porção superior da Formação Jaíba.

Juntos, laminitos e trombólitos apresentam cinco microtexturas, as quais representam tanto processos biogênicos de formação, tais como as microtexturas micrítica e mosqueada, quanto abiogênicos, como é o caso da microtextura peloidal. Também se discutiu a natureza da microtextura micrítica, identificada nos trombólitos. Esta ocorrência não encontra análogos na literatura e pode representar uma nova textura trombolítica o que, no entanto, carece de estudos mais abrangentes para confirmação.

Duas formas de microfósseis foram encontradas e compreendem formas filamentosas, associadas aos trombólitos, e formas cocoidais, associadas aos laminitos. Mesmo em face à sua preservação ruim, estes microfósseis revelam o potencial a ser explorado que a Formação Jaíba representa para conhecermos melhor a paleobiota produtora da transição Ediacarano-Cambriano. Neste momento, a diversificação dos metazoários e o consequente estabelecimento de novas relações ecológicas, sobretudo entre produtores e consumidores primários representados pelos primeiros metazoários, marcam um momento-chave na evolução da vida no Planeta Terra (e.g. Awramik, 1971; Riding, 2006; Xiao \& Laflamme, 2009).

\section{AGRADECIMENTOS}

Os autores agradecem à Fundação de Amparo à Pesquisa de Minas Gerais pela bolsa de iniciação científica concedida à T.A.V., sob o número 3652017, a qual faz parte do projeto Microbialitos de Minas Gerais, registrado na PRPPG/UFVJM sob o número 11082016. Agradecem também ao Laboratório de Laminação do CeGeo/UFVJM, seu técnico, L. Souza, e ao prof. D. Barbuena (ICT/UFVJM) pela confecção de lâminas petrográficas. Por fim, agradecem aos revisores que muito colaboraram na melhora do texto, enriquecendo-o.

\section{REFERÊNCIAS}

Aitken, J.D. 1967. Classification and environmental significance of cryptalgal limestones and dolomites, with illustrations from the Cambrian and Ordovician of southwestern Alberta. Journal of Sedimentary Research, 37:1163-1178. doi:10.1306/74D7185C2B21-11D7-8648000102C1865D

Alkmim, F.F. 2004. O que faz de um cráton um cráton? O Cráton do São Francisco e as revelações almeidianas ao delimitá-lo. In: V. Mantesso-Neto; V.A. Bartorelli; C.D.R. Carneiro \& B.B. BritoNeves (eds.) Geologia do continente sul americano: evolução da obra de Fernando Flávio Marques de Almeida, Beca, p. 17-35. 
Alkmim, F.F. \& Martins-Neto, M.A. 2001. A bacia intracratônica do São Francisco: arcabouço estrutural e cenários evolutivos. In: C.P. Pinto \& M.A. Martins-Neto (eds.) Bacia do São Francisco: geologia e recursos naturais, SBG-MG, p. 9-30.

Atman, D. 2011. Controle lito-estrutural e estratigráfico na hidrogeoquímica e nas concentrações de fluoreto no sistema aquífero cárstico-fissural do Grupo Bambuí, norte de Minas Gerais. Programa de Pós-Graduação em Geologia, Universidade Federal de Minas Gerais, Tese de Mestrado, 131 p.

Awramik, S.M. 1971. Precambrian columnar stromatolite diversity: reflection of metazoan appearance. Science, 174:825-827. doi:10.1126/science.174.4011.825

Babinski, M.; Vieira, L.C. \& Trindade, R.I.P. 2007. Direct dating of the Sete Lagoas cap carbonate (Bambuí Group, Brazil) and implications for the Neoproterozoic glacial events. Terra Nova, 19:401-406. doi:10.1111/j.1365-3121.2007.00764.x

Bartley, J.K.; Knoll, A.H.; Grotzinger, J.P. \& Sergeev, V.N. 2000. Lithification and fabric genesis in precipitated stromatolites and associated peritidal carbonates, Mesoproterozoic Billyakh Group, Siberia. In: J.P. Grotzinger \& N.P. James (eds.) Carbonate sedimentation and diagenesis in the evolving Precambrian world, Tulsa, Society for Sedimentary Geology, p. 59-73 (Special Publication 67).

Braga, J.C.; Martin, J.M. \& Riding, R. 1995. Controls on microbial dome fabric development along a carbonate-siliciclastic shelfbasin transect, Miocene, SE Spain. Palaios, 10:347-361. doi: $10.2307 / 3515160$

Buick, R., 1990. Microfossil recognition in Archean rocks: an appraisal of spheroids and filaments from a 3500 my old chertbarite unit at North Pole, Western Australia. Palaios, p. 441-459

Burne, R. \& Moore, L. 1987. Microbialites: organosedimentary deposits of benthic microbial communities. Palaios, 2:241-254. doi:10.2307/3514674

Castro, P.T.A. \& Dardenne, M.A. 2000. The sedimentology, stratigraphy and tectonic context of the São Francisco Supergroup at the southwest boundary of the São Francisco Craton, Brazil. Revista Brasileira de Geociências, 30:439-441.

Caxito, F.A.; Halverson, G.P.; Uhlein, A.; Stevenson, R.; Dias, T.G. \& Uhlein, G.J. 2012. Marinoan glaciation in east central Brazil. Precambrian Research, 200:38-58. doi:10.1016/j. precamres.2012.01.005

Chiavegatto, J.R.S.; Gomes, N.S.; Dardenne, M.A. \& Delgado, C.E.R. 2003. Estratigrafia do Grupo Bambuí nas regiões do norte de Minas Gerais: uma nova unidade estratigráfica em um contexto de inversão de bacia. In: SIMPÓSIO DE GEOLOGIA DE MINAS GERAIS, 12, 2003. Resumos expandidos, Ouro Preto, SBG, p. 24.

Corsetti, F.A. \& Grotzinger, J.P. 2005. Origin and significance of tube structures in Neoproterozoic post-glacial cap carbonates: example from Noonday Dolomite, Death Valley, United States. Palaios, 20:348-362. doi:10.2110/palo.2003.p03-96

Costa, M.T. \& Branco, J.J.R. 1961. Roteiro de excursão Belo Horizonte-Brasília. In: CONGRESSO BRASILEIRO DE GEOLOGIA, 15, 1961. Resumos expandidos, Florianópolis, SBG, p. 9-25.

Coulson, K.P. 2016. The growth and ecology of Upper Cambrian microbialite biostromes from the Notch Peak Formation in Utah. Loma Linda University, Ph.D. Thesis, 367 p.

Dardenne, M.A. 1981. Os grupos Paranoá e Bambuí na Faixa
Dobrada Brasília. In: SIMPÓSIO SOBRE O CRÁTON DO SÃO FRANCISCO E SUAS FAIXAS MARGINAIS, 1, 1979. Boletim de Resumos, Salvador, SBG, p. 104-157.

Défrage, C.; Trichet, J.; Jaunet, A.M.; Robert, M.; Tribble, J. \& Sansone, F.J. 1996. Texture of microbial sediments revealed by cryo-scanning electron microscopy. Journal of Sedimentary Research, 66:935-947. doi:10.1306/D4268446-2B26-11D7$8648000102 C 1865 D$

Dunham, R.J. 1962. Classification of carbonate rocks according to their depositional texture. In: W.E. Ham (ed.) Classification of Carbonate Rocks - a symposium, Tulsa, American Association of Petroleum Geologists, p. 108-121 (Memoir 1).

Fairchild, T.R. \& Sanchez, E.A.M. 2015. Microbialitos no Brasil: panorâmica de ocorrências e guia de caracterização morfológica. In: T.R. Fairchild; R. Rohn \& D. Dias-Brito (eds) Microbialitos do Brasil: do Pré-Cambriano ao Recente, IGCE/UNESP, p. 22-41.

Fantinel, L.M.; Knauer, L.G.; Correa Pereira, D.F.L.; Fonte Boa, T.M.R. \& Horta, R.M. 2015. Folha Manga SD.23-Z-A-VI e Folha Carinhanha SD.23-Z-A-III Escala 1:100.000. In: A.C.P. (Org.) Projeto Fronteiras de Minas Gerais, CODEMIG, p. 1-44.

Flügel, E. 2010. Microfacies of carbonate rocks: analysis, interpretation and application. $2^{\text {nd }}$ ed. Berlim, Springer-Verlag, 1006 p. doi:10.1007/978-3-662-08726-8

Fragoso, D.G.C.; Uhlein, A.; Sanglard, J.C.D.; Suckau, G.L.; Guerzoni, H.T.G. \& Faria, P.H. 2011. Geologia dos grupos Bambuí, Areado e Mata da Corda na folha Presidente Olegário (1: 100.000), MG: registro deposicional do Neoproterozóico ao Neocretáceo da Bacia do São Francisco. Geonomos, 19:28-38. doi:10.18285/geonomos.v19i1.60

Grotzinger, J.P. \& Knoll, A.H. 1999. Stromatolites in Precambrian carbonates: evolutionary mileposts or environmental dipsticks? Annual Review of Earth and Planetary Sciences, 27:313-358. doi:10.1146/annurev.earth.27.1.313

Grotzinger, J.P.; Watters, W.A. \& Knoll, A.H. 2000. Calcified metazoans in thrombolite-stromatolite reefs of the terminal Proterozoic Nama Group, Namibia. Paleobiology, 26:334-359. doi:10.1666/0094-8373(2000)026<0334:CMITSR>2.0.CO;2

Guerra-Sommer, M.; Lemos, V.B.; Medeiros, R.A.; Terra, G.J.S. \& Pereira, C.P. 1993. Trombólitos (?) da Formação Salitre, Chapada Diamantina (Bahia), Brasil. In: CONGRESSO BRASILEIRO DE PALEONTOLOGIA, 13, 1993. Boletim de Resumos, São Leopoldo, SBP, p. 204.

Hofmann, H. J. 1969. Attributes of stromatolites. Canadá: Department of Energy, Mines and Resources, p. 1-58.

Hofmann, H.J. 1976. Precambrian microflora, Belcher Islands, Canada: significance and systematics. Journal of Paleontology, 50:1040-1073.

Iglesias, M. \& Uhlein, A. 2009. Estratigrafia do Grupo Bambuí e coberturas fanerozóicas no vale do rio São Francisco, norte de Minas Gerais. Revista Brasileira de Geociências, 39:256-266.

Knoll, A.H. \& Golubic, S. 1979. Anatomy and taphonomy of a Precambrian algal stromatolite. Precambrian Research, 10:115-151. doi:10.1016/0301-9268(79)90022-6

Kuchenbecker, M. 2014. Relações entre coberturas do Cráton do São Francisco e bacias situadas em orógenos marginais: o registro de datações $\mathrm{U}-\mathrm{Pb}$ de grãos detríticos de zircão e suas implicações geotectônicas. Programa de Pós-Graduação em Geologia, Universidade Federal de Minas Gerais, Dissertação Doutorado, $174 \mathrm{p}$. 
Kuchenbecker, M.; Atman, D. \& Costa, R.D. 2013a. Mapa geológico 1:100.000 da Folha Barreiro do Jaiba (SD.23-Z-C-VI). Belo Horizonte, Projeto Norte de Minas, Codemig/UFMG.

Kuchenbecker, M.; Atman, D.; Costa, R.D.; Pedrosa-Soares, A.C. \& Babinski, M. 2016. A Formação Gorutuba: sedimentação litorânea a continental na margem leste da Bacia Bambuí (MG). Geologia USP-Série Científica, 16:67-81. doi:10.11606// issn.2316-9095.v16i2p67-81

Kuchenbecker, M.; Babinski, M.; Pedrosa-Soares, A.C.; Costa, R.D.; Lopes-Silva, L. \& Pimenta, F. 2013b. Proveniência e análise sedimentar da porção basal do Grupo Bambuí em Arcos (MG). Geologia USP-Série Científica, 13:49-61. doi:10.5327/Z1519$874 X 201300040003$

Kuchenbecker, M.; Costa, D.A. \& Costa, R.D. 2014. Folha Barreiro da Jaiba - SE.23-Z-C-IV. Belo Horizonte, Projeto Norte de Minas, Codemig/UFMG.

Kuchenbecker, M. \& Pedrosa-Soares, A.C. 2010. O Grupo Bambuí na folha Luz (SE-23-Y-D-V). Geonomos, 18:46-52.

Macintyre, I.G. \& Reid, R.P. 1978. Micritization. In: C.W. Finkl (ed.) Sedimentology, Springer, p. 713-717. doi:10.1007/9781-4020-3609-5_136

Martins, M. \& Lemos, V.L. 2007. Análise estratigráfica das sequências neoproterozoicas da Bacia do São Francisco. Revista Brasileira de Geociências, 37:156-167.

Martins-Neto, M.A. 2009. Sequence stratigraphic framework of Proterozoic successions in eastern Brazil. Marine and Petroleum Geology, 26:163-176. doi:10.1016/j.marpetgeo.2007.10.001

Monty, C.L.V. 1976. The origin and development of cryptalgal fabrics. In: M.R. Walter (ed.) Stromatolites, New York, Elsevier, p. 93-249 (Developments in Sedimentology 20). doi:10.1016/ S0070-4571(08)71137-3

Paula-Santos, G.M.; Babinski, M.; Kuchenbecker, M.; CaetanoFilho, S.; Trindade, R.I. \& Pedrosa-Soares, A.C. 2015. New evidence of an Ediacaran age for the Bambuí Group in southern São Francisco craton (eastern Brazil) from zircon $\mathrm{U}-\mathrm{Pb}$ data and isotope chemostratigraphy. Gondwana Research, 28:702-720. doi:10.1016/j.gr.2014.07.012

Pimentel, M.M.; Rodrigues, J.B.; DellaGiustina, M.E.S.; Junges, S.; Matteini, M. \& Armstrong, R. 2011. The tectonic evolution of the Neoproterozoic Brasília Belt, central Brazil, based on SHRIMP and LA-ICPMS U-Pb sedimentary provenance data: a review. Journal of South American Earth Sciences, 31:345-357. doi:10.1016/j.jsames.2011.02.011

Reis, H.L.S.; Alkmim, F.F.; Fonseca, R.C.S.; Suss, J.F.; Nascimento, T.C. \& Prrevatti, L.D. 2017a. The São Francisco Basin. In: M. Heilbron; U.G. Cordani \& F. Alkmim (eds.) São Francisco Craton, Eastern Brazil: tectonic Genealogy of a miniature continent, Springer, p. 117-143. doi:10.1007/978-3-319-01715$0 \_7$

Reis, H.L.S. \& Suss, J. 2016. Mixed carbonate-siliciclastic sedimentation in forebulge grabens: an example from the Ediacaran Bambuí Group, São Francisco Basin, Brazil. Sedimentary Geology, 339:83-103. doi:10.1016/j. sedgeo.2016.04.004

Reis, H.L.S.; Suss, J.F.; Fonseca, R.C.S. \& Alkmin, F.F. 2017 b. Ediacaran forebulge grabens of the Southern São Francisco basin, SE Brazil: craton interior dynamics during West Gondwana assembly. Precambrian Research, 302:150-170. doi:10.1016/j.precamres.2017.09.023
Ribeiro, A.; Paciulo, F.V.P.; Senra, A.S.; Valeriano, C.M. \& Trouw, R.A.J. 2008. Geologia da Folha de Pimhi SF.23-V-B-2. Rio de Janeiro, Programa Geologia do Brasil (CPRM-UFRJ). Disponível em: http://rigeo.cprm.gov.br/xmlui/handle/ doc/10468; acessado em 07/08/2018.

Riding, R. 2006. Microbial carbonate abundance compared with fluctuations in metazoan diversity over geological time. Sedimentary Geology, 185:229-238. doi:10.1016/j. sedgeo.2005.12.015

Riding, R. 2011. Microbialites, stromatolites, and thrombolites. In: J. Reitner \& V. Thiel (eds.) Encyclopedia of geobiology, Springer, p. 635-654. doi:10.1007/978-1-4020-9212-1_196

Rodrigues, J.B. 2008. Proveniência de sedimentos dos grupos Canastra, Ibiá, Vazante e Bambuí - Um estudo de zircões detríticos e Idades Modelo SM-Nd. Programa de Pós-Graduação em Geologia, Universidade de Brasília, Tese de doutoramento, $128 \mathrm{p}$.

Sanchez, E.A.M. 2014. Microbialitos e microfósseis da Formação Sete Lagoas, Neoproterozoico, Brasil: implicações geomicrobiológicas em um contexto de mudanças climáticas e evolutivas. Programa de Pós-Graduação em Geoquímica e Geotectônica, Universidade de São Paulo, Tese de Doutoramento, 298 p.

Santos, D.M. 2018. Caracterização das ocorrências de microbialitos na Formação Lagoa do Jacaré, Grupo Bambuí, do Estado de Minas Gerais e suas implicações paleobiológicas e sedimentológicas. Programa de Pós-graduação em Geologia, Universidade de Brasília, Dissertação de Mestrado, 116 p.

Santos, R.V.; Alvarenga, C.J.S.; Babinski, M.; Ramos, M.L.S.; Cukrov, N.; Fonseca, M.A.; Sial, A.N.; Dardenne, M.A. \& Noce, C.M. 2004. Carbon isotopes of Mesoproterozoic-Neoproterozoic sequences from Southern São Francisco craton and Araçuaí Belt, Brazil: Paleographic implications. Journal of South American Earth Sciences, 18: 27-39.

Seong-Joo, L.; Browne, K.M. \& Golubic, S. 2000. On stromatolite lamination. In: R. Riding \& S.M. (eds.) Microbial sediments, Springer, p. 16-24. doi:10.1007/978-3-662-04036-2_3

Shapiro, R.S. 2000. A comment on the systematic confusion of thrombolites. Palaios, 15:166-169. doi:10.1669/08831351(2000)015<0166: ACOTSC > 2.0.CO;2

Signorelli, N. 2009. Folha SE.23-Y-D-III Abaeté: Projeto Sete Lagoas - Abaeté. Belo Horizonte. Programa Geologia do Brasil, CPRM. Disponível em: http://rigeo.cprm.gov.br/jspui/handle/ doc/10939; acessado em 07/08/2018.

Soudry, D. \& Weissbrod, T. 1995. Morphogenesis and facies relationships of thrombolites and siliciclastic stromatolites in a Cambrian tidal sequence (Elat area, southern Israel). Palaeogeography, Palaeoclimatology, Palaeoecology, 114:339355. doi:10.1016/0031-0182(94)00087-O

Turner, E.C.; James, N.P. \& Narbonne, G.M. 2000. Taphonomic control on microstructure in Early Neoproterozoic reefal stromatolites and thrombolites. Palaios, 15:87-111. doi:10.1669/0883-1351(2000)015<0087:TCOMIE>2.0.CO;2

Uhlein, A.; Ersinzon, F.; Uhlein, G.J. \& Alcântara, D.G. 2017. Estratigrafia e sistemas deposicionais do Supergrupo Espinhaço e grupos Bambuí e Macaúbas: roteiro de campo na Serra do Espinhaço Meridional (MG). Terrae Didatica, 13:244-257. doi:10.20396/td.v13i3.8650963

Uhlein, G.J.; Uhlein, A.; Halverson, G.P.; Stevenson, R.; Caxito, F.A.; Cox, G.M. \& Carvalho, J.F. 2016. The Carrancas Formation, 
Bambuí Group: a record of pre-Marinoan sedimentation on the southern São Francisco craton, Brazil. Journal of South American Earth Sciences, 71:1-16. doi:10.1016/j.jsames.2016.06.009

Vasconcelos, C. \& Bahniuk, A. 2015. Microbialitos recentes da região dos Lagos, Estado do Rio de Janeiro. In: T.R. Fairchild; R. Rohn \& D. Dias-Brito (eds.) Microbialitos do Brasil: do PréCambriano ao Recente, IGCE/UNESP, p. 60-75.

Vieira, L.C.; Trindade, R.I.F.; Nogueira, A.C.R. \& Ader, M. 2007. A Formação Sete Lagoas em sua área-tipo: fácies, estratigrafia. Brazilian Journal of Geology, 37: 168-181.

Walter, M.R.; Grotzinger, J.P. \& Schopf, J.W. 1992. Proterozoic stromatolites. In: J.W. Schopf \& C. Klein (eds.) The Proterozoic biosphere: a multidisciplinary study, Cambridge University Press, p. 253-260.

Walter, M.R. \& Heys, G.R. 1985. Links between the rise of the Metazoa and the decline of stromatolites. Precambrian Research, 29:149-174. doi:10.1016/0301-9268(85)90066-X

Warren, L.V.; Quaglio, F.; Riccomini, C.; Simões, M.G.; Poiré, D.G.; Strikis, N.M.; Anelli, L.E. \& Strikis, P.C. 2014. The puzzle assembled: Ediacaran guide fossil Cloudina reveals an old proto-Gondwana seaway. Geology, 42:391-394. doi:10.1130/ G35304.1
Whalen, M.T.; Day, J.; Eberli, G.P. \& Homewood, P.W. 2002. Microbial carbonates as indicators of environmental change and biotic crises in carbonate systems: examples from the Late Devonian, Alberta basin, Canada. Palaeogeography, Palaeoclimatology, Palaeoecology, 181:127-151. doi:10.1016/ S0031-0182(01)00476-X

Wood, R. 2015. Microbialitos e a evolução de recifes através do tempo. In: T.R. Fairchild; R. Rohn \& D. Dias-Brito (eds.) Microbialitos do Brasil: do Pré-Cambriano ao Recente, IGCE/ UNESP, p. 42-59.

Xiao, S. \& Laflamme, M. 2009. On the eve of animal radiation: phylogeny, ecology and evolution of the Ediacara biota. Trends in Ecology \& Evolution, 24:31-40. doi:10.1016/j.tree.2008.07.015

Zalán, P.V. \& Romeiro-Silva, P.C. 2007. Bacia do São Francisco. Boletim de Geociências da Petrobras, 15:561-570.

Received in 28 February, 2018; Accepted in 05 July, 2018. 